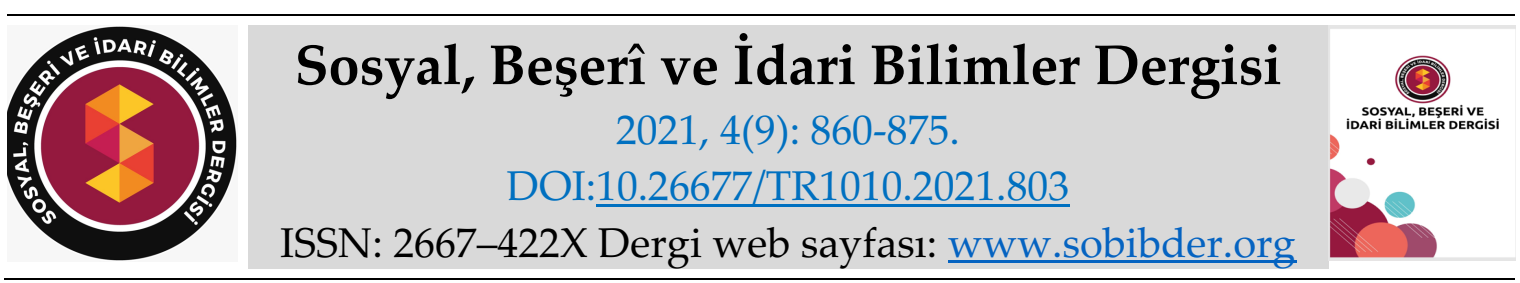

ARAŞTIRMA MAKALESI

\title{
Bağımsız Denetçi Değişikliğinin Belirleyicileri: BİST Şirketleri Üzerine Bir Araştırma
}

\author{
Öğr. Gör. Dr. Neşegül PARLAK, Ordu Üniversitesi, Fatsa Meslek Yüksekokulu, Ordu, e-posta: \\ nparlak@odu.edu.tr \\ ORCID: https://orcid.org/0000-0002-1669-7389
}

\section{Öz}

Küreselleşme, gelişen teknoloji ve değişen ekonomik sistemlerin oluşturduğu zorlu rekabet ortamında, finansal bilgi kullanıcılarının kararlarını etkileyen finansal bilgi güvenliğinin arttırılmasında, denetçi bağımsızlığının sağlanması ve denetimin kalitesi bağlamında bağımsız denetim kuruluşu rotasyonu ve bağımsız denetçi değişikliği önem arz eden bir konudur. Çalışma, Türkiye'de Borsa İstanbul (BİST)'da işlem gören şirketlerin bağımsız denetim kuruluşu değiştirme durumunun, denetlenecek şirketin bulunduğu il, faaliyet gösterdiği sektör ve bağımsız denetçinin görüşü ile ilişkisini yıllar bazında tespit etmek amacıyla yapılmıştır. Araştırmanın kapsamında, yasal olarak finansal tablolarını denetletme zorunluluğu bulunan Borsa İstanbul (BİST TUM) XUTUM endeksinde işlem gören 477 şirketin 2015-2020 yılları arası bağımsız denetim raporları incelenmiştir. Araştırma sonuçlara göre, bağımsız denetim kuruluşu değiştirme oranları yıllar bakımından il, sektör, görüş durumlarına göre ayrı ayrı değerlendirildiğinde anlamlı değişimler tespit edilmiştir. Panel regresyon modelinde ise il, faaliyet gösterdiği sektör ve bağımsız denetçinin görüşü değişkenlerinin, bağımsız denetim kuruluşu değiştirme durumu üzerinde anlamlı bir etkisinin bulunmadığı tespit edilmiştir.

Anahtar Kelimeler: Bağımsız Denetim, Denetçi Değişikliği, Panel Veri Analizi.

Makale Gönderme Tarihi: 09.06.2021

Makale Kabul Tarihi: 03.09.2021

\section{Önerilen Atıf:}

Parlak, N. (2021). Bağımsız Denetçi Değişikliğinin Belirleyicileri: BİST Şirketleri Üzerine Bir Araştırma, Sosyal, Beşeri ve İdari Bilimler Dergisi, 4(9): 860-875.

(c) 2021 Sosyal, Beşerî ve İdari Bilimler Dergisi. 


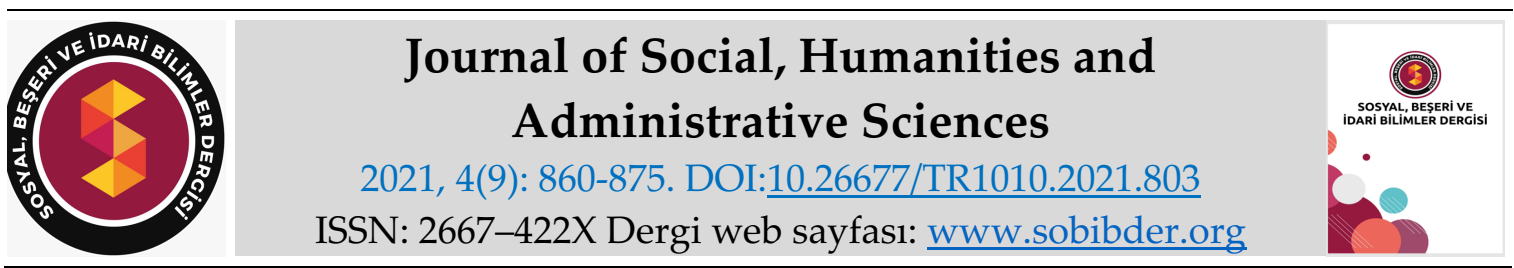

RESEARCH PAPER

\title{
Determinants of Independent Auditor Change: A Study on BIST Companies
}

Dr. Neşegül PARLAK, Ordu University, Fatsa Vocational School, Ordu, e-mail: nparlak@odu.edu.tr

ORCID: https://orcid.org/0000-0002-1669-7389

\begin{abstract}
Independent auditing firm rotation and independent auditor change is a significant issue in the context of globalization, in a challenging competitive environment created by developing technology and changing economic systems, in enhancing financial information security that affects the decisions of financial information users, ensuring auditor independence and the quality of the auditing. The study was carried out in order to determine the relationship between the change of independent audit firm of companies traded in Borsa Istanbul (BIST) in Turkey, the province where the company to be audited, the sector in which it operates and the opinion of the independent auditor on a yearly basis. Within the scope of the research, the independent audit reports of 477 companies traded in the Borsa Istanbul (BIST TUM) XUTUM index, which are legally obliged to have their financial statements audited, between the years 2015-2020 were examined. According to the results of the research, when the rates of changing independent audit firms are evaluated separately in terms of province, sector and opinion, significant changes are detected. In the panel regression model, it has been determined that the variables of the province, the sector in which it operates and the opinion of the independent auditor do not have a significant effect on the change of independent audit firm.
\end{abstract}

Keywords: Independent Audit, Auditor Change, Panel Data Analysis.

Received: 09.06.2021

Accepted: 03.09.2021

\section{Suggested Citation:}

Parlak, N. (2021). Determinants of Independent Auditor Change: A Study on BIST Companies, Journal of Social, Humanities and Administrative Sciences, 4(9): 860-875.

(C) 2021 Sosyal, Beşerî ve İdari Bilimler Dergisi. 


\section{Gíriş}

Küresel rekabet ortamında, gelişen teknoloji ile değişen ekonomik sistemlerde, finansal bilgi kullanıcılarının kararlarını etkileyen finansal bilgi güvenirliliğin arttırılmasında bağımsız denetimin önemli rolü ve sorumluluğu bulunmaktadır. Bu noktada, bağımsız denetime tabi şirketlerin finansal bilgi kullanıcılarına güvenilir bilgi sunulmasında bağımsız denetim kuruluşu seçimi önemli bir konudur. Küreselleşme, teknolojik ve ekonomik gelişmelerin etkisiyle güvenilir finansal bilgiye ihtiyaç duyan bilgi kullanıcılarının artması, muhasebe sistemleri tarafından üretilen finansal bilginin şeffaf, ihtiyaca uygun ve güvenilir nitelikte olma gerekliliği artmıştır. Finansal bilgi kullanıcılarının, güvenilir olmayan finansal bilgiler ile aldıkları ekonomik kararların, kaynakların verimli kullanılmasına engel olması ve finansal bilgi kullanıcılarının yanı sıra toplumun büyük bir bölümünü zarara uğratması nedeniyle ekonomik alanda güvenirlilik ihtiyacı artmıştır (Sayar ve Karataş, 2017:15). Ulusal ve uluslararası ekonomik piyasalarda faaliyet gösteren şirketlerin finansal bilgilerine ihtiyaç duyan bilgi kullanıcılarının, finansal kararlarını doğru verebilmeleri için söz konusu şirketlere ilişkin finansal bilgilerin doğru, şeffaf, ve güvenilir olmasına bağlıdır (Yazar, Güneş ve Çukacı, 2018:1072).

Bağımsız denetim kuruluşunun zorunlu rotasyonu dışında şirketlerin bağımsız denetim kuruluşu değişikliklerinin nedenlerinin bilinmesi, bağımsız denetçi değişikliğine ilişkin finansal bilgi kullanıcılarına önemli ipuçları verebilir. Türkiye'de mevcut durumda bağımsız denetime tabi şirketlerin bağımsız denetim kuruluşu değişikliğine gitme nedenlerini kamuoyuna bildirme zorunluluğu bulunmamaktadır. Bu çalışma, şirketlerin denetçi değiştirme durumunun, bağımsız denetçinin görüşünün, şirketin faaliyet gösterdiği il ve şirketin faaliyet gösterdiği sektöre göre etkisinin bulunup bulunmadığını tespit etmek ve yıllar bazında bağımsız denetim kuruluşu değişikliğinin tespit etmek üzere yapılmıştır. Bu amaçla, BİST'te işlem gören 477 şirketin 20152020 yılları arasındaki bağımsız denetim kuruluşu değiştirme durumunun ilgili değişkenler kapsamında incelenmiştir. Yapılan literatür taramasında daha önceki çalışmalarda söz konusu değişkenler ve örneklem grubu üzerinde bir çalışmaya rastlanmadığından bu çalışmanın literatüre katkı sağlayacağı düşünülmektedir.

\section{BAĞIMSIZ DENETIM KAVRAMI ve BAĞIMSIZ DENETIMDE ROTASYON}

Bağımsız denetim, uluslararası finansal raporlama standartları (UFRS) ile uyumlu bir denetim sistemidir. Bağımsız denetim, bağımsız denetçilerin işletmenin finansal bilgileri ile ilgilenen finansal bilgi kullanıcılarına, finansal tabloların finansal raporlama standartlarına uygunluğu hakkında görüss vermek ve finansal bilgilerin güvenilirliği hakkında güvence vermektedir. Bağımsız denetim mesleğinin temelinde yer alan bağımsızlık kavramı önemlidir. Küreselleşme ile uluslararası ekonomik piyasaların genişlemesi ve yaşanan teknolojik gelişmeler, bağımsız denetim mesleğinin önemini daha da arttırmıştır (Mackintosh, 2014:2). Bağımsız denetimin amacı, denetlenen şirketin finansal tablolarının hata ve hile kaynaklı önemli bir yanlışlık bulunmadığı yönünde finansal bilgi kullanıcılarına makul düzeyde bir güvence sağlamaktır. Bağımsız denetim ile finansal tablo ve bilgilerin tüm önemli yönleri ile gerçeğe uygun, tam ve doğru sunulup sunulmadığına ilişkin bir görüş bildirilmektedir. Bağımsız denetçinin görüşüne güvenen finansal bilgi kullanıcıları, kararlarını bu güven duygusu ile bağımsız denetim görüşü doğrultusunda vermektedir (Şavlı, 2016:40). Bu yönü ile bağımsız denetim, kurumsal yönetimin ve hesap verebilir olmanın güvencesi rolündedir (Cömert, Uzay, Kardeş Selimoğlu ve Uyar, 2015:1).

Uluslararası alanda, finansal raporlama uygulamaları ile desteklenen denetimde standartlaşma çalışmaları neticesinde, Uluslararası Denetim Standartları (UDS) ortaya çıkmış ve standart ile 
hem denetimin ve denetçinin bağımsızlı̆̆ı sağlanmış hem de denetim faaliyetlerinin güvenilirliğinin sağlanması hedeflenmiştir (Bekçi ve Gör, 2015:167). UDS paralelinde Türkiye'de de 6102 sayılı Yeni Türk Ticaret Kanunu (TTK) ile ekonomik yaşamda bağımsız denetim ön plana çıkarılmış ve şirketlerin kurumsal yönetim ilkelerine uygun faaliyet yürütmesi ve şeffaflığın sağlanması ve küresel rekabet gücünün arttırılması amacıyla, Kamu Gözetimi Muhasebe ve Denetim Standartları Kurumu (KGK) kurulmuştur. Türkiye'de TTK öncesinde denetim alanındaki çalışmalar açısından SPK bünyesindeki halka açık şirketlerin denetim komitesi ve riskin erken saptanması komitesi oluşturmaları zorunlu hale getirilmiştir (Karataş, 2014:124).

Finansal bilgi kullanıcılarının kararlarının dayanağı olan finansal tablolarda sunulan finansal bilgilerin güvenilirliğinin arttırılmasında bağımsız denetim önemli bir rol üstlenmektedir (Yaşar, 2015:82). Şirketlerin bağımsız denetime tabi tutmalarının zorunlu tutulmasının nedenleri olarak;

- Finansal bilgi kullanıcıları arasında ortaya çıkması muhtemel çıkar çatışmaları,

- Küreselleşme, ekonomik ve teknolojik gelişmeler vb. nedenlerle finansal bilgi kullanıcılarının sayısındaki artış,

- Finansal bilgi kullanıcılarının bu bilgiler ile aldıkları kararlardan toplumun büyük bir bölümünün etkilemesi,

- Finansal bilgi kullanıcılarının ihtiyaç duydukları finansal bilgilerin birinci elden temin edilmesinin mümkün olmaması,

Bağımsız denetim faaliyetine ilişkin yasal düzenlemeler, faaliyet sürecinde yol gösterici olmaktadır ancak, bağımsız denetim kuruluşunun büyüklüğü, organizasyon yapısı ve tecrübesi verilen denetim hizmetinin kalitesinde etkili olan faktörlerden en önemlilerinin başında gelmektedir (Kurt, 2015:28). Bağımsız denetçinin, finansal tablolardaki önemli yanlışlıkları tespit edip, bu yanlışlıkları denetim raporuna yansıtması sunulan denetim hizmetinin kaliteli olarak değerlendirilmesini sağlar (Mohammed ve Habib, 2013:127).

Uluslararası piyasalarda yaşanan 2001 Enron skandalı ve sonrasında yaşanan skandallar neticesinde, denetimde kalite anlayışı, güven ve itibar arayışları beraberinde kurumsallaşmayı gündeme getirmiştir. Denetimde kurumsallaşma ve kurumsal yönetim anlayışı ile birlikte şeffaflık, adillik, hesap verilebilirlik ve sorumluluk ilkeleri ön plana çıkarılarak, denetim alanındaki boşlukların doldurulması ve finansal bilgi kullanıcılarının korunması hedeflenmiştir (Cengiz ve Gör, 2016: 62).

Bağımsız denetimde rotasyon, şirketi denetleyen bağımsız denetim kuruluşunun belirli bir süre sonunda söz konusu şirketin denetimine ara vermek zorunda kalması ve söz konusu şirketin denetimini ancak belirlenen bir süreden sonra tekrar üstlenebilmesini ifade eder. Bağımsız denetimde rotasyon uygulamasının amacı, bağımsız denetim kuruluşu/bağımsız denetçi ile denetlenen şirket arasındaki ilişkilerin bir menfaat birliğinin kurulmasına neden olabilecek niteliğe dönüşmesini engellemektir (Arslan, 2010:206). Bağımsız denetimin kalitesinin arttırılması ve denetçi bağımsızlığının sağlanması amacıyla denetçi rotasyonu ile ilgili ulusal ve uluslararası kuruluşlar tarafından birçok düzenleme yapılmıştır (Gönen ve Rasgen, 2016:1810). Türkiye' de bağımsız denetçi değişikliğiyle ilgili düzenlemelere ilişkin sürekli olarak değişiklikler yapıldığı görülmektedir. Yapılan söz konusu düzenlemeler denetçi rotasyonunu resmen getirmektedir.

Literatürde, bağımsız denetim kuruluşu/bağımsız denetçilere uygulanan zorunlu rotasyonun, denetçi bağımsızlığını sağlaması yönü ile denetimin kalitesini arttıracağı görüşü hakim olmakla birlikte, bağımsız denetim kuruluşunun denetlenen şirket ile uzun süreli denetim ilişkisini sürdürmesine yönelik farklı görüşler mevcuttur. Bağımsız denetim faaliyetini yürüten bağımsız 
denetçinin aynı şirket ile uzun süreli ilişkisi şirket yönetimi ile denetçi arasında bir yakınlaşma ve çıkar ilişkisi ortaya çıkabilecek, bu durum denetçinin mesleki şüphecilik anlayışını ve bağımsızlığını zedeleyecektir (Mohammed ve Habib 2013; Lennox vd., 2014; Salleh ve Jasmani 2014). Bağımsız denetçilerin zorunlu rotasyonu denetimin kalitesini arttırmakta ve denetçi bağımsızlığını güçlendirmektedir (Gönen ve Rasgen, 2016:1815). Bağımsız denetçi ile müşteri şirketin, uzun süreli iş ilişkisi sonucunda elde edilen bilgi birikimi denetim riskini düşürmektedir (Harris 2012; Cameran vd., 2014).

Tablo 1. Türkiye'deki Bağımsız Denetçi Rotasyonu ile İlgili Düzenlemeler

\begin{tabular}{|c|c|c|c|}
\hline Kuruluş & $Y_{11}$ & Değişiklik & Açıklama \\
\hline \multirow[t]{4}{*}{$\begin{array}{l}\text { Sermaye Piyasası Kurulu } \\
\text { (SPK) }\end{array}$} & $\begin{array}{l}2002 \text { yılı Seri:X No:19 sayılı } \\
\text { Tebliğ }\end{array}$ & 5 yıllık rotasyon & $\begin{array}{l}\text { Sorumlu ortak baş } \\
\text { denetçi (SOBD) en az } 2 \\
\text { hesap dönemi için } \\
\text { rotasyon getirilmiştir. }\end{array}$ \\
\hline & $\begin{array}{l}2006 \text { yılı Seri:X No:22 sayılı } \\
\text { Tebliğ }\end{array}$ & 7 yıllık rotasyon & $\begin{array}{l}\text { Sorumlu ortak baş } \\
\text { denetçi (SOBD) en az } 2 \\
\text { hesap dönemi için } \\
\text { rotasyon getirilmiştir. }\end{array}$ \\
\hline & 2009 yılı Seri: X, No:25 & 7 yılı geçen rotasyon & $\begin{array}{lr}\text { SOBD } & \text { rotasyonu } \\
\text { uygulamak } & \text { koşuluyla } \\
\text { rotasyon } & \text { süresi } \\
\text { uzatılabilir. } & \end{array}$ \\
\hline & $\begin{array}{l}2011 \text { y1lı Seri:X No: } 27 \text { sayıl1 } \\
\text { Tebliğ }\end{array}$ & SOBD için 5 yıllık rotasyon & $\begin{array}{l}\text { SOBD aynı şirketi } \\
\text { denetleyebilmesi için en } \\
\text { az } 2 \text { yıl geçmesi gerekir. }\end{array}$ \\
\hline $\begin{array}{l}6102 \text { Sayılı Türk Ticaret } \\
\text { Kanunu }\end{array}$ & 400/2. Md. & $\begin{array}{l}\text { Aynı şirket için } 10 \text { yıl } \\
\text { içinde toplam } 7 \text { yıl denetçi } \\
\text { olarak seçilen denetçi için } 3 \\
\text { yıllık rotasyon }\end{array}$ & $\begin{array}{l}\text { KGK, bu uygulanmaya } \\
\text { ilişkin usul ve esasları } \\
\text { belirlemeye ve bu } \\
\text { fbelirtilen süreleri } \\
\text { kisaltmaya yetkilidir. }\end{array}$ \\
\hline $\begin{array}{ll}\text { Bağımsız } & \text { Denetim } \\
\text { Yönetmeliği } & \end{array}$ & 26/1-ç md. & $\begin{array}{l}\text { Denetim kuruluşları için, } \\
\text { son } 10 \text { yılda } 7 \text { yıl, } \\
\text { Denetçiler için ise, denetim } \\
\text { kuruluşunda da çalışanlar } \\
\text { da dahil olmak üzere son } 7 \\
\text { yılda } 5 \text { yıl denetimini } \\
\text { yaptıkları şirketler için } 3 \\
\text { yıllık rotasyon }\end{array}$ & $\begin{array}{lr}\text { Bu } & \text { sürelerin } \\
\text { hesaplanmasında aynı } \\
\text { denetim ağ içinde } \\
\text { bulunan kuruluşlar ile } \\
\text { ilişkili denetim } \\
\text { kuruluşları tarafından } \\
\text { yapılan denetimlerde } \\
\text { geçen süreler topluca } \\
\text { dikkate alınacaktır (26/2. } \\
\text { md.). }\end{array}$ \\
\hline \multirow{2}{*}{$\begin{array}{lr}\text { Bankacıllk } & \text { Düzenleme ve } \\
\text { Denetleme } & \text { Kurumu } \\
\text { (BDDK) } & \end{array}$} & 2006 yilında & 8 yıllık rotasyon & \\
\hline & 2011 yılında & 5 yıllık SOBD rotasyonu & $\begin{array}{l}\text { Asgari } 3 \text { yıl ve azami } 8 \\
\text { y1llık bağımsız denetim } \\
\text { kuruluşu rotasyonu }\end{array}$ \\
\hline
\end{tabular}

\section{LITERATÜR TARAMASI}

Ulusal ve Uluslararası literatür incelendiğinde; bağımsız denetime tabi şirketlerin bağımsız denetçi değişikliğini konu alan çalışmalar bulunmaktadır. Yapılan çalışmaların büyük çoğunluğunda bağımsız denetim kuruluşu/bağımsız denetçi değişikliğine ilişkin en önemli faktörlerden biri olarak olumsuz denetim görüşü incelenmiştir. Literatürde yer alan çalışmalardan bazıları aşağıda yer almaktadır.

Chow ve Rice (1982) çalışmasında, şirketin geçmiş döneme ilişkin finansal tablolarına bağımsız denetim görüşünün şartlı görüş olması şirketin hisse değerini etkileyeceğinden, olumlu görüş 
alma olasılı̆̆ını arttırmak için mevcut dönemde denetim kuruluşunu değiştirme yoluna gitmekte olduğunu belirtmiştir.

Craswell (1988) tarafından, Avustralya'da yapılan çalışmada, bağımsız denetim kuruluşunun olumsuz denetim görüşü vermesi sonrasında şirket yönetiminin çoğunlukla denetçi değişikliğine gittikleri ve yeni denetçilerin de olumlu denetim görüşü verdikleri tespit edilmiştir.

Gul vd., (1992) tarafından, Hong Kong'da yapılan çalışmada, bağımsız denetim kuruluşunun olumsuz denetim görüşü vermesi ve sonrasındaki bağımsız denetçi değişikliği arasında anlamlı bir şekilde pozitif bir ilişki olduğu tespit edilmiştir.

Dye (1991) tarafından yapılan çalışmada, bağımsız denetçinin şartlı denetim raporu vermesinin muhtemel olması durumunda, şirketin büyük ihtimalle bağımsız denetçi değişikliğine gideceği görülmüştür.

Teoh (1992) tarafından yapılan çalışmada, olumsuz denetçi görüşü verilmesi sonrasında şirketlerin denetçi değişikliğine gitmesindeki artışın nedeni olarak, bağımsız denetçinin şirket yönetiminin taleplerini yerine getirmek yerine ilgili kural ve yöntemleri izlemesi ile tutarlı olduğu tartışılmıştır.

Lennox (2000) tarafından İngiltere'de borsaya kote olan toplamda 1988-1994 yılları arasında 5441 şirketin verisi üzerine yapılan çalışmada, bağımsız denetçiler tarafından, olumsuz denetim görüşü verilen şirketlerin çoğunlukla bağımsız denetçilerini değiştirdikleri ve bağımsız denetçi değişikliği sonrasında ise olumlu denetim görüşü verilme olasılığının arttığı yönünde iki önemli tespit yapılmıştır.

Hudaib ve Cooke (2005) tarafından yapılan çalışmada, bağımsız denetim raporunda şartlı görüş verilen şirketlerden; finansal yönden sıkıntıda olmayan ve üst düzey yöneticisini değiştirenlerin, finansal yönden sıkıntıda olan ve üst düzey yöneticisini değiştirmeyen şirketlere göre bağımsız denetim kuruluşu değiştirme sıklığının daha fazla olduğu tespit edilmiştir.

Chan vd., (2006) tarafından yapılan çalışmada, bağımsız denetim kuruluşunun şartlı görüş vermesinden sonra gerçekleşen bağımsız denetim kuruluşu değişikliğinin yönünün yabancı denetim kuruluşlarından yerel denetim kuruluşlarına doğru olduğunu tespit etmişlerdir.

Davidson III, Jiraporn ve DaDalt (2006) tarafından yapılan çalışmada, geçmiş dönemde olumlu görüş verilmeyen şirketlerin mevcut dönemde bağımsız denetim kuruluşu değişikliğine gittiği tespit edilmiştir.

Blandon ve Bosch (2013) tarafından yapılan çalışmada, İspanya Borsası'nda yer alan şirketlerin 2001-2009 yılları arasında yaptığı panel veri tahminlerine göre şirketlerin denetçi bağımlılığı ile denetim raporları arasında anlamlı bir ilişki olmadığı saptanmıştır.

Salleh ve Jasmani (2014) tarafından yapılan çalışmada, bağımsız denetim görüşünün, şirketlerin bağımsız denetim kuruluşu değişikliğine gitmesinde önemli bir faktör olmadığını tespit etmişlerdir.

Stanisic ve diğerleri (2014) tarafından yapılan çalışmada, geçmiş dönemde sınırlı olumlu görüş verilen şirketlerin, mevcut dönemde denetçi değişikliğine gitmesinin olumlu denetim görüşüne sahip şirketlere göre daha fazla ortaya çıktığı tespit edilmiştir.

Yaşar (2015) tarafından, olumsuz denetçi görüşü ve bağımsız denetçi değişikliği arasındaki ilişkiyi incelemek amacıyla, Borsa İstanbul'da işlem gören sanayi şirketleri üzerine yapılan çalışma sonucunda, olumsuz denetim görüşü ile bağımsız denetçi değişikliği arasında anlamlı bir ilişki olduğu tespit edilmiştir. 
Literatür incelemesi sonucu yapılan çalışmalar değişkenler açısından özet olarak Tablo 2'de verilmiştir.

Tablo 2. Literatür İnceleme Özeti

\begin{tabular}{|l|l|}
\hline Değişkenler & Yapılan Çalışmalar \\
\hline Bağımsız Denetçi Görüşü & (Chow ve Rice 1982; Schwartz ve Menon 1985; Williams 1988; \\
& $\begin{array}{l}\text { Craswell 1988; Haskins ve Williams 1990; Dye 1991; Teoh } \\
\text { 1992, Gul vd., 1992; Krishnan vd., 1996; Lennox, 2000; Woo ve } \\
\text { Koh 2001; Chan, Lin ve Mo, 2006; Davidson III, Jiraporn, } \\
\text { DaDalt, 2006; Salleh ve Jasmani 2014; Yaşar 2015; 2016) }\end{array}$ \\
\hline Yönetimdeki Değişiklikler & $\begin{array}{l}\text { (Burton ve Roberts 1967; Carpenter ve Strawser 1971; Hudaib } \\
\text { ve Cooke 2005) }\end{array}$ \\
\hline $\begin{array}{l}\text { Müşteri İşletmenin } \\
\text { Büyüklüğü }\end{array}$ & (Gul vd., 1992; Krishnan vd., 1996; Willenborg, 1999) \\
\hline $\begin{array}{l}\text { Bağımsız Denetim } \\
\text { Kuruluşunun Türü }\end{array}$ & $\begin{array}{l}\text { (Warren, 1980; Chow ve Rice, 1982; Craswell, 1988; Krishnan } \\
\text { vd., 1996) }\end{array}$ \\
\hline Denetim Ücretleri & (DeAngelo, 1981; Wines, 1994; DeFond vd., 2002; Craswell vd., \\
& 2002) \\
\hline Finansal Problemler & (Schwartz ve Menon 1985; Hudaib ve Cooke 2005) \\
\hline
\end{tabular}

\section{ARAŞTIRMA}

Borsa İstanbul (BİST)'da işlem gören ve dolayısıyla finansal tablolarını zorunlu ve ciddi olarak denetletmek zorunda olan 477 şirketin 2015-2020 yılları arası bağımsız denetim kuruluşlarını değiştirme durumlarını etkileyen faktörler incelenmiştir.

\section{Araştırmanın Amacı, Kapsamı ve Yöntemi}

Türkiye'de Borsa İstanbul (BİST)'da işlem gören şirketlerin bağımsız denetim kuruluşu değiştirme durumunun, denetlenecek şirketin bulunduğu il, faaliyet gösterdiği sektör ve bağımsız denetçinin görüşü ile ilişkisini yıllar bazında tespit etmek amacıyla yapılmıştır. Bu amaçla, BİST'te işlem gören 477 şirketin 2015-2020 yılları arasındaki sürekli bağımsız denetim raporları www.kap.org.tr internet sitesinden çekilerek araştırma kapsamına alınmıştır. Araştırmanın amacı doğrultusunda, yıllara göre kuruluş değişim oranları hesaplanmış ve dönemler arasında bu oranlar arasındaki farklılıkların istatistiksel olarak anlamlı olup olmadığ iki oran karşılaştırma testleri ile sınanmıştır. Oran testlerinde iki karşılaştırmalar için Bonferroni düzeltmesi uygulanmıştır. Analiz kapsamında oransal karşılaştırmalar hem şehir hem de sektör bazında ayrı ayrı yapılmıştır. Kuruluş değiştirme durumunu modelleme yaklaşımı ile değerlendirmek için bağımlı değişkenin kategorik olması sonucu Probit Panel Regresyon analizi kullanılmıştır. Uygulamalar R-Project yazılımı (R Core Team, 2021) içerisinde yer alan pglm (Croissant, 2020) ve biostat (Gegzna, 2020) paketleri ile gerçekleştirilmiştir.

Panel regresyon modellerinde bağımlı değişkenin kategorik olması durumunda lojistik panel regresyon analizi uygulanmaktadır. Probit panel regresyon analizinde farklı zaman periyotlarında ele alınan gözlem birimleri kullanılarak, seçilen bağımsız değişkenlerin kategorik bağımlı değişken üzerinde istatistiksel olarak anlamlı etki yaratıp yaratmadığı incelenir. Probit panel regresyon analizine ilişkin regresyon denklemi aşağıdaki gibi yazılır: 


$$
\phi^{-1}\left(\pi\left(x_{i t}\right)\right)=x_{i t}{ }^{T} \beta
$$

(1) Eşitlik

$1^{\prime}$ de $\mathrm{i}=1,2, . ., \mathrm{n}$ birimleri, $\mathrm{t}=1,2, \ldots, \mathrm{T}$ zaman periyodunu, $\phi($.$) standart normal dağılım fonksiyonun$ tersini, $\pi($.$) ilgili olayın gerçekleşme olasılığı, x$ bağımsız değişkenleri, $\beta$ ise panel regresyon katsayılarını gösterir (Karlson vd., 2012; Kalkavan ve Ersin, 2019).

\section{ARAŞTIRMANIN BULGULARI}

Araştırmanın amacı ve kapsamı çerçevesinde, yapılan analizler sonucu elde edilen bulgular aşağıda yer almaktadır. İller için yıllık bazda bağımsız denetim firması değiştirme analiz sonuçları Tablo 3'te verilmiştir.

Tablo 3. Şehirlere Göre Bağımsız Denetim Kuruluşu Değişim Sonuçları

\begin{tabular}{|c|c|c|c|c|c|}
\hline \multirow{2}{*}{ Şehir } & \multicolumn{5}{|c|}{ Değişim \% } \\
\hline & 2015-2016 & 2016-2017 & $2017-2018$ & 2018-2019 & 2019-2020 \\
\hline Adana & 33.3 & 66.7 & 0 & 66.7 & 100 \\
\hline Amasya & 0 & 0 & 0 & 100 & 0 \\
\hline Ankara & $31^{\mathrm{ab}}$ & $75.9^{c}$ & $10.3^{\mathrm{a}}$ & $65.5^{\mathrm{bc}}$ & $72.4^{\mathrm{c}}$ \\
\hline Antalya & 100 & 0 & 100 & 100 & 100 \\
\hline Aydın & 0 & 66.7 & 0 & 100 & 66.7 \\
\hline Balıkesir & 0 & 100 & 0 & 100 & 100 \\
\hline Bolu & 100 & 100 & 0 & 100 & 0 \\
\hline Bursa & $30.8^{\mathrm{ab}}$ & $76.9^{\mathrm{b}}$ & $7.7^{\mathrm{a}}$ & $76.9^{\mathrm{b}}$ & $53.8^{\mathrm{ab}}$ \\
\hline Çanakkale & 0 & 100 & 0 & 100 & 100 \\
\hline Denizli & 50 & 100 & 0 & 50 & 100 \\
\hline Erzincan & 0 & 100 & 0 & 100 & 100 \\
\hline Gaziantep & 100 & 0 & 0 & 100 & 100 \\
\hline Hatay & 100 & 100 & 0 & 100 & 0 \\
\hline Isparta & 66.7 & 66.7 & 0 & 66.7 & 66.7 \\
\hline İstanbul & $46.6^{\mathrm{a}}$ & $55.7^{\mathrm{a}}$ & $19^{\mathrm{b}}$ & $73.5^{c}$ & $77.5^{\mathrm{c}}$ \\
\hline İzmir & $48.5^{\mathrm{a}}$ & $63.6^{\mathrm{ab}}$ & $0^{c}$ & $87.9^{\mathrm{b}}$ & $75.8^{\mathrm{ab}}$ \\
\hline Kahramanmaraş & 100 & 0 & 0 & 100 & 100 \\
\hline Karabük & 100 & 100 & 0 & 0 & 100 \\
\hline Kayseri & 57.1 & 57.1 & 0 & 57.1 & 71.4 \\
\hline Kırşehir & 0 & 100 & 0 & 100 & 100 \\
\hline Kocaeli & $53.8^{\mathrm{ab}}$ & $53.8^{\mathrm{ab}}$ & $0^{\mathrm{a}}$ & $84.6^{\mathrm{b}}$ & $76.9^{\mathrm{b}}$ \\
\hline Konya & 50 & 75 & 0 & 100 & 50 \\
\hline Kütahya & 50 & 50 & 0 & 100 & 100 \\
\hline Manisa & 100 & 50 & 0 & 50 & 50 \\
\hline Mardin & 0 & 100 & 0 & 100 & 100 \\
\hline Mersin & 100 & 100 & 0 & 100 & 100 \\
\hline Niğde & 66.7 & 66.7 & 0 & 100 & 100 \\
\hline Samsun & 100 & 100 & 0 & 100 & 100 \\
\hline Tekirdağ & 100 & 50 & 0 & 50 & 100 \\
\hline Uşak & 0 & 50 & 0 & 50 & 100 \\
\hline Yalova & 0 & 0 & 0 & 100 & 0 \\
\hline Yozgat & 0 & 100 & 0 & 100 & 0 \\
\hline
\end{tabular}


Tablo 3'te şehirlere göre yıllar arası bağımsız denetim kuruluşu değişim oranları ve karşılaştırma sonuçları verilmiştir. Karşılaştırma sonuçlarına göre, Ankara, Bursa, İstanbul, İzmir ve Kocaeli şehirlerinde yıllar arası bağımsız denetim kuruluşu değişim oranları açısından anlamlı farklılık bulunmuştur $(\mathrm{p}<0.05)$. Oran karşılaştırmalarına göre Ankara'da 2016-2017 ve 2019-2020 dönemindeki kuruluş değiştirme oranı 2015-2016 ve 2017-2018 dönemine göre anlamlı ölçüde daha fazladır. Benzer şekilde Ankara'da 2018-2019 dönemindeki kuruluş değiştirme oranı 20172018 dönemine göre anlamlı ölçüde daha yüksektir.

Sonuçlara bakıldığında Bursa' da 2015-2016 ve 2019-2020 dönemlerinde kuruluş değiştirme oranı 2016-2017 ve 2018-2019 dönemlerine göre anlamlı ölçüde daha düşüktür. Benzer şekilde Bursa' da 2017-2018 döneminde kuruluş değiştirme oranı 2016-2017 ve 2018-2019 dönemlerine göre anlamlı ölçüde daha düşüktür.

Bu sonuçlara göre İstanbul' da 2015-2016 ve 2016-2017 dönemlerinde bağımsız denetim kuruluşu değiştirme oranı 2018-2019 ve 2019-2020 dönemlerine göre anlamlı ölçüde daha düşüktür. Ayrıca İstanbul' da 2017-2018 döneminde kuruluş değiştirme oranı diğer dönemlere göre anlamlı ölçüde daha düşüktür.

Sonuçlara bakıldığında İzmir'de 2016-2017 ve 2019-2020 dönemlerinde bağımsız denetim kuruluşu değiştirme oranı 2018-2019 dönemine göre anlamlı ölçüde düşük, 2015-2016 dönemine göre ise anlamlı ölçüde daha yüksektir.

Karşılaştırma sonuçlarına göre Kocaeli'nde 2018-2019 ve 2019-2020 dönemlerinde bağımsız denetim kuruluşu değiştirme oranı 2015-2016 ve 2016-2017 yıllarına göre anlamlı ölçüde daha yüksektir. Sektörlere göre bağımsız denetim kuruluşu değişim sonuçları Tablo 4'te verilmiştir.

Tablo 4. Sektörlere Göre Bağımsız Denetim Kuruluşu Değişim Sonuçları

\begin{tabular}{lccccc}
\hline \multirow{2}{*}{ Sektör } & \multicolumn{5}{c}{ Değişim \% } \\
\cline { 2 - 6 } & $\mathbf{2 0 1 5 - 2 0 1 6}$ & $\mathbf{2 0 1 6 - 2 0 1 7}$ & $\mathbf{2 0 1 7 - 2 0 1 8}$ & $\mathbf{2 0 1 8 - 2 0 1 9}$ & $\mathbf{2 0 1 9 - 2 0 2 0}$ \\
\hline $\begin{array}{l}\text { Eğitim, Sağllk, Spor ve Diğer } \\
\text { Sosyal Hizmetler }\end{array}$ & 50 & 50 & 0 & 100 & 100 \\
\hline Elektrik Gaz ve Su & 50 & 50 & 0 & 83.3 & 50 \\
\hline Gayrimenkul Faaliyetleri & 50 & 100 & 0 & 100 & 100 \\
\hline $\begin{array}{l}\text { İdari ve Destek Hizmet } \\
\text { Faaliyetleri }\end{array}$ & 100 & 100 & 0 & 0 & 100 \\
\hline İmalat & $47.9^{\mathrm{a}}$ & $60.7^{\mathrm{ab}}$ & $4.3^{\mathrm{c}}$ & $77.9^{\mathrm{d}}$ & $73.6^{\mathrm{bd}}$ \\
\hline İnşaat ve Bayındırlık & 55.6 & 66.7 & 0 & 66.7 & 66.7 \\
\hline Madencilik ve Taş Ocakçılığı & 100 & 0 & 0 & 100 & 100 \\
\hline Mali Kuruluşlar & $43.5^{\mathrm{a}}$ & $57.8^{\mathrm{ab}}$ & $26.6^{\mathrm{c}}$ & $71.4^{\mathrm{bd}}$ & $81.2^{\mathrm{d}}$ \\
\hline $\begin{array}{l}\text { Mesleki, Bilimsel ve Teknik } \\
\text { Faaliyetler }\end{array}$ & 0 & 100 & 0 & 100 & 100 \\
\hline Tarım, Ormancılık ve Balıkçllık & 50 & 50 & 0 & 100 & 50 \\
\hline Teknoloji & 53.8 & 76.9 & 15.4 & 69.2 & 61.5 \\
\hline $\begin{array}{l}\text { Toptan ve Perakende Ticaret, } \\
\text { Lokantalar ve Oteller }\end{array}$ & $41.4 \mathrm{ab}$ & $51.7^{\mathrm{ac}}$ & $6.9^{\mathrm{b}}$ & $86.2^{\mathrm{c}}$ & $75.9^{\mathrm{ac}}$ \\
\hline $\begin{array}{l}\text { Ulaştırma, Depolama ve } \\
\text { Haberleşme }\end{array}$ & 25 & 75 & 12.5 & 62.5 & 62.5 \\
\hline
\end{tabular}


Tablo 4' te, sektörlere göre bağımsız denetim kuruluşu değişim oranları ve karşılaştırma sonuçları verilmiştir. Karşılaştırma sonuçlarına göre imalat, mali kuruluşlar, toptan ve perakende ticaret, lokanta ve otel sektörlerinde yıllar arası bağımsız denetim kuruluşu değişim oranları açısından anlamlı farklılık bulunmuştur ( $\mathrm{p}<0.05)$. Farklılıklar incelendiğinde 2015-2016 döneminde imalat sektöründe bağımsız denetim kuruluşu değişim oranı, 2018-2019 yıllarına göre anlamlı ölçüde daha düşük, 2017-2018 dönemine göre ise anlamlı ölçüde daha yüksektir. Sonuçlara göre 20152016 dönemi mali kuruluşlar sektöründe bağımsız denetim kuruluşu değişme oranı 2019-2020 dönemine göre anlamlı ölçüde daha düşük, 2017-2018 dönemine göre anlamlı ölçüde daha yüksektir. Ayrıca sonuçlara bakıldığında 2016-2017 ve 2019-2020 dönemlerinde toptan ve perakende ticaret ve lokantalar ve otel sektöründe bağımsız denetim kuruluşu değişme oranı 2018-2019 döneminde anlamlı ölçüde daha düşük, 2017-2018 dönemine göre anlamlı ölçüde daha yüksektir. Bağımsız denetim görüşüne göre bağımsız denetim kuruluşu değiştirme sonuçları Tablo 5 'te görülmektedir.

Tablo 5. Görüşlere Göre Bağımsız Denetim Kuruluşu Değişim Sonuçları

\begin{tabular}{lccccc}
\hline \multirow{2}{*}{ Görüsş } & \multicolumn{5}{c}{ Değişim \% } \\
\cline { 2 - 6 } & $\mathbf{2 0 1 5 - 2 0 1 6}$ & $\mathbf{2 0 1 6 - 2 0 1 7}$ & $\mathbf{2 0 1 7 - 2 0 1 8}$ & $\mathbf{2 0 1 8 - 2 0 1 9}$ & $\mathbf{2 0 1 9 - 2 0 2 0}$ \\
\hline Şartlı (2015) & $60.5^{\mathrm{b}}$ & $60.5^{\mathrm{b}}$ & $21.1^{\mathrm{a}}$ & $71.1^{\mathrm{b}}$ & $84.2^{\mathrm{b}}$ \\
Olumlu (2015) & $44.2^{\mathrm{a}}$ & $59.8^{\mathrm{b}}$ & $12.7^{\mathrm{c}}$ & $75.9^{\mathrm{d}}$ & $75.1^{\mathrm{d}}$ \\
\hline Şartlı (2016) & $66.7^{\mathrm{b}}$ & $52.8^{\mathrm{ab}}$ & $22.2^{\mathrm{a}}$ & $63.9^{\mathrm{b}}$ & $77.8^{\mathrm{b}}$ \\
& & & & $76.6^{\mathrm{d}}$ & $75.8^{\mathrm{d}}$ \\
\hline Olumlu (2016) & $43.7^{\mathrm{a}}$ & $60.6^{\mathrm{b}}$ & $12.7^{\mathrm{c}}$ & $76.8^{\mathrm{b}}$ \\
Şartlı (2017) & $60.6^{\mathrm{ab}}$ & $63.6^{\mathrm{ab}}$ & $27.3^{\mathrm{a}}$ & $63.6^{\mathrm{ab}}$ & $81.8^{\mathrm{b}}$ \\
Olumlu (2017) & $44.4^{\mathrm{a}}$ & $59.5^{\mathrm{b}}$ & $12.3^{\mathrm{c}}$ & $76.5^{\mathrm{d}}$ & $75.4^{\mathrm{d}}$ \\
\hline Şartlı (2018) & $59^{\mathrm{b}}$ & $48.7^{\mathrm{ab}}$ & $17.9^{\mathrm{a}}$ & $53.8^{\mathrm{b}}$ & $76.9^{\mathrm{b}}$ \\
Olumlu (2018) & $44.3^{\mathrm{a}}$ & $61.1^{\mathrm{b}}$ & $13.1^{\mathrm{c}}$ & $77.8^{\mathrm{d}}$ & $75.9^{\mathrm{d}}$ \\
\hline Şartll (2019) & $48.8^{\mathrm{b}}$ & $46.5^{\mathrm{ab}}$ & $16.3^{\mathrm{a}}$ & $65.1^{\mathrm{b}}$ & $76.7^{\mathrm{b}}$ \\
Olumlu (2019) & $45.4^{\mathrm{a}}$ & $61.5^{\mathrm{b}}$ & $13.2^{\mathrm{c}}$ & $76.7^{\mathrm{d}}$ & $75.9^{\mathrm{d}}$ \\
\hline
\end{tabular}

Tablo 5'te görüşlere göre denetim kuruluşu değişim oranları ve karşılaştırma sonuçları verilmiştir. Karşılaştırma sonuçlarına bakıldığında tüm görüşlere göre yıllar arası bağımsız denetim kuruluşu değişim oranları açısından anlamlı farklılık bulunmuştur $(\mathrm{p}<0.05)$. Farklılıklar incelendiğinde şartlı (2015)' göre 2017-2018 döneminde kuruluş değişim oranı diğer dönemlere göre anlamlı ölçüde daha düşüktür. Sonuçlara göre olumlu (2015)'e göre 2018-2019 ve 2019-2020 dönemlerinde kuruluş değişim oranları diğer dönemlere göre anlamlı ölçüde daha yüksektir. Benzer şekilde olumlu (2015)'e göre 2015-2016 döneminde kuruluş değişim oranı 2016-2017 dönemine göre daha düşük, 2017-2018 dönemine göre anlamlı ölçüde daha yüksektir. Sonuçlara bakıldığında şartlı (2016)'ya göre 2017-2018 döneminde kuruluş değişim oranı diğer dönemlere göre anlamlı ölçüde daha düşüktür. Ayrıca olumlu (2016)'ya göre 2018-2019 ve 2019-2020 dönemlerinde kuruluş değişim oranları diğer dönemlere göre anlamlı ölçüde daha yüksektir. Benzer şekilde olumlu (2016)'e göre 2015-2016 döneminde kuruluş değişim oran 2016-2017 dönemine göre daha düşük, 2017-2018 dönemine göre anlamlı ölçüde daha yüksektir.

Sonuçlara bakıldı̆̆ında şartlı (2017)'ye göre 2015-2016, 2016-2017 ve 2018-2019 dönemlerinde kuruluş değişim oranları, 2019-2020 dönemine göre daha düşük, 2017-2018 dönemine göre anlamlı ölçüde daha yüksektir. 
Sonuçlara göre olumlu (2017)'e göre 2018-2019 ve 2019-2020 dönemlerinde kuruluş değişim oranları diğer dönemlere göre anlamlı ölçüde daha yüksektir. Benzer şekilde olumlu (2017)'e göre 2015-2016 döneminde kuruluş değişim oranı 2016-2017 dönemine göre daha düşük, 20172018 dönemine göre anlamlı ölçüde daha yüksektir. Sonuçlara bakıldığında şartlı (2018)'e göre 2017-2018 döneminde kuruluş değişim oranı diğer dönemlere göre anlamlı ölçüde daha düşüktür. Sonuçlara göre olumlu (2018)'e göre 2018-2019 ve 2019-2020 dönemlerinde kuruluş değişim oranları diğer dönemlere göre anlamlı ölçüde daha yüksektir. Benzer şekilde olumlu (2018)'e göre 2015-2016 döneminde kuruluş değişim oranı 2016-2017 dönemine göre daha düşük, 2017-2018 dönemine göre anlamlı ölçüde daha yüksektir.

Sonuçlara bakıldığında şartlı (2019)'a göre 2017-2018 döneminde kuruluş değişim oranı diğer dönemlere göre anlamlı ölçüde daha düşüktür. Sonuçlara göre olumlu (2019)'a göre 2018-2019 ve 2019-2020 dönemlerinde kuruluş değişim oranları diğer dönemlere göre anlamlı ölçüde daha yüksektir. Benzer şekilde olumlu (2019)'a göre 2015-2016 döneminde kuruluş değişim oranı 20162017 dönemine göre daha düşük, 2017-2018 dönemine göre anlamlı ölçüde daha yüksektir.

Probit panel regresyon modelinde bağımsız değişkenlerin bağımsız denetim firması değiştirme durumu üzerinde etkisini gösteren istatistiksel analizi sonuçları Tablo 6'da görülmektedir.

Tablo 6. Probit Panel Regresyon Analizi Sonuçları

\begin{tabular}{lcccc}
\hline Katsayı & OR & SH & t-istatistiği & p \\
\hline Sabit Terimi & 1.394 & 0.525 & 0.633 & 0.527 \\
\hline Görüş (Olumlu) & 0.989 & 0.100 & -0.112 & 0.911 \\
\hline Elektrik Gaz ve Su & 0.705 & 0.471 & -0.744 & 0.457 \\
\hline Gayrimenkul Faaliyetleri & 1.332 & 0.587 & 0.488 & 0.625 \\
\hline İdari ve Destek Hizmet Faaliyetleri & 0.962 & 0.699 & -0.056 & 0.955 \\
\hline İmalat & 0.789 & 0.411 & -0.578 & 0.563 \\
\hline İnşaat ve Bayındırlık & 0.781 & 0.447 & -0.552 & 0.581 \\
\hline Madencilik ve Taş Ocakçılığı & 0.973 & 0.698 & -0.040 & 0.968 \\
\hline Mali Kuruluşlar & 0.885 & 0.408 & -0.299 & 0.765 \\
\hline Mesleki, Bilimsel ve Teknik Faaliyetler & 0.973 & 0.698 & -0.040 & 0.968 \\
\hline Tarım, Ormancılık ve Balıkçlık & 0.755 & 0.569 & -0.494 & 0.621 \\
\hline Teknoloji & 0.866 & 0.436 & -0.330 & 0.742 \\
\hline Toptan ve Perakende Ticaret, Lokantalar ve Oteller & 0.781 & 0.420 & -0.588 & 0.557 \\
\hline Ulaştırma, Depolama ve Haberleşme & 0.721 & 0.451 & -0.726 & 0.468 \\
\hline Amasya & 0.396 & 0.716 & -1.292 & 0.197 \\
\hline Ankara & 0.899 & 0.345 & -0.309 & 0.757 \\
\hline Antalya & 2.154 & 0.727 & 1.055 & 0.291 \\
\hline Aydın & 0.849 & 0.460 & -0.357 & 0.721 \\
\hline Balıkesir & 1.185 & 0.516 & 0.329 & 0.742 \\
\hline Bolu & 1.185 & 0.653 & 0.260 & 0.795 \\
\hline Bursa & 0.875 & 0.362 & -0.371 & 0.711 \\
\hline Çanakkale & 1.185 & 0.653 & 0.260 & 0.795 \\
\hline Denizli & 1.185 & 0.516 & 0.329 & 0.742 \\
\hline Erzincan & 1.185 & 0.653 & 0.260 & 0.795 \\
\hline Gaziantep & 1.196 & 0.665 & 0.269 & 0.788 \\
\hline & & & & \\
\hline
\end{tabular}




\begin{tabular}{lcccc}
\hline Hatay & 1.182 & 0.654 & 0.256 & 0.798 \\
\hline Isparta & 1.034 & 0.467 & 0.072 & 0.942 \\
\hline İstanbul & 0.961 & 0.331 & -0.121 & 0.904 \\
\hline İzmir & 1.046 & 0.339 & 0.132 & 0.895 \\
\hline Kahramanmaraş & 1.182 & 0.654 & 0.256 & 0.798 \\
\hline Karabük & 1.185 & 0.653 & 0.260 & 0.795 \\
\hline Kayseri & 0.886 & 0.387 & -0.312 & 0.755 \\
\hline Kur & 1.185 & 0.653 & 0.260 & 0.795 \\
\hline Kocaeli & 0.996 & 0.360 & -0.011 & 0.991 \\
\hline Konya & 0.984 & 0.434 & -0.037 & 0.970 \\
\hline Kütahya & 1.185 & 0.516 & 0.329 & 0.742 \\
\hline Manisa & 0.920 & 0.512 & -0.163 & 0.870 \\
\hline Mardin & 1.185 & 0.653 & 0.260 & 0.795 \\
\hline Mersin & 2.122 & 0.718 & 1.049 & 0.294 \\
\hline Niğde & 1.413 & 0.466 & 0.742 & 0.458 \\
\hline Samsun & 2.134 & 0.716 & 1.058 & 0.290 \\
\hline Tekirdağ & 1.185 & 0.516 & 0.329 & 0.742 \\
\hline Uşak & 0.674 & 0.516 & -0.764 & 0.445 \\
\hline Yalova & 0.396 & 0.716 & -1.292 & 0.197 \\
\hline Yozgat & 0.714 & 0.653 & -0.516 & 0.606 \\
\hline
\end{tabular}

OR: Odds oran1; SH: Standart hata

Tablo 6'da kuruluş değiştirme durumları için elde edilmiş probit panel regresyon analizi sonuçları verilmiştir. Panel regresyon modelinde şehir grupları, sektör grupları ve kuruluş görüşü değişkenlerinin bağımlı değişken olan kuruluş değiştirme durumu üzerinde anlamlı etkisi bulunamamıştır ( $\mathrm{p}>05$ ). Bağımsız değişkenlerin istatistiksel olarak anlamsız olması; sektör, şehir ve görüş değişkenlerinin model açısından anlamsız olduğuna işaret etmektedir.

\section{SONUÇ ve TARTIŞMA}

Ekonomik ve teknolojik gelişmeler, finansal bilgi kullanıcılarının en doğru bilgiye ulaşabilmeleri açısından şirketlerin finansal tablolarının bağımsız denetimden geçmiş olması oldukça önemlidir. Ulusal ve uluslararası düzenleyici kuruluşlar tarafından, bağımsız denetimin bağımsızlı̆̆ını yitirmemesine yönelik yenilikler getirilmektedir. Türkiye'de söz konusu düzenleyici kuruluşlar tarafından yapılan düzenlemelere göre zorunlu haller dışında, bağımsız denetçi seçimi müşteri şirketin iradesine bırakılmıştır.

Bu çalışmada, şirketlerin bağımsız denetçi değiştirme durumuna, bağımsız denetçinin görüşü, şirketin faaliyet gösterdiği il ve şirketin faaliyet gösterdiği sektörün etkisi ve şirketlerin bağımsız denetçi değiştirme durumunun araştırma kapsamındaki yıllar içerisindeki durumu araştırılmıştır.

Borsa İstanbul (BİST)'da işlem gören ve dolayısıyla finansal tablolarını yasa gereği denetletmek zorunda olan 477 şirketin 2015-2020 yılları arası bağımsız denetim kuruluşlarını değiştirme durumlarını etkileyen faktörler incelenmiştir. Çalışmanın istatistiksel analiz bulgularına göre; Ankara, İstanbul, İzmir, Bursa ve Kocaeli illerinde bağımsız denetim kuruluşları değiştirme 
oranlarının yıllar arasında istatistiksel olarak anlamlı ölçüde farklılaştığı belirlenmiştir. İllere göre özellikle 2016-17 ve 2018-2019 yılları arasında bağımsız denetim kuruluşu değişim oranlarının yükseldiği gözlenmiştir. Sektörler açısından bakıldığında İmalat, Mali Kuruluşlar ve Toptan ve Perakende Ticaret, Lokantalar ve Oteller sektörlerinde bağımsız denetim kuruluşları değiştirme oranlarının yıllar arasında istatistiksel olarak anlamlı ölçüde farklılaştığı tespit edilmiştir. Sektörlere göre özellikle 2018-19 ve 2019-2020 yılları arasında bağımsız denetim kuruluşu değişim oranlarının yükseldiği gözlenmiştir. Görüşler açısından değerlendirildiğinde, ele alınan tüm yıl grupları arasında bağımsız denetim kuruluşları değiştirme oranları anlamlı ölçüde değişmiştir. Denetim kuruluşlarına ait görüşlere göre özellikle 2018-19 ve 2019-2020 yılları arasında bağımsız denetim kuruluşu değişim oranlarının yükseldiği belirlenmiştir. Panel veri analizi ile elde edilen probit panel regresyon modellerinde kuruluşlara ait görüşler, iller ve çalışılan sektörler bağımsız denetim kuruluşu değişim durumu üzerinde istatistiksel olarak anlamlı bir etki oluşturmamaktadır. Bu sonuçlara göre bağımsız denetim kuruluş değiştirme oranları yıllar bazında ve il, sektör, görüş durumlarına göre ayrı ayrı değerlendirildiğinde anlamlı değişimler gözlenmişken; lojistik panel regresyon modelinde bağımsız denetim kuruluş değiştirme durumu olarak incelendiğinde il, sektör, görüş durumlarının istatistiksel olarak anlamsız olduğu görülmüştür.

Ulusal ve uluslararası literatür incelendiğinde bağımsız denetim kuruluşu değişikliğini etkileyen faktörlere ilişkin çeşitli çalışmalar bulunmaktadır. Ancak yapılan çalışmalar çoğunlukla denetçi görüşünün bağımsız denetim kuruluşu değişikliğine etkisini tespit etmeye yöneliktir. Bu çalışmada, bağımsız denetçi görüşünün yanı sıra, denetlenen şirketin faaliyet gösterdiği il ve şirketin faaliyet gösterdiği sektörün denetim kuruluşu değişikliği üzerinde etkisi araştırma kapsamındaki yıllar bazında incelenmiştir. Gelecekteki çalışmalar, şirketlerin, bağımsız denetim kuruluşu değiştirme durumunun analizi ve tahminine yönelik farklı değişkenler ve analiz teknikleri kullanılarak yapılabilir.

\section{KAYNAKÇA}

Arslan, E. (2010). Bağımsız Denetimde Rotasyon Karmaşası. Mali Çözüm Dergisi, 99, 201-227.

Bankacılık Düzenleme ve Denetleme Kurumu (2006). Bankaların Bağımsız Denetim Gerçekleştirecek Kuruluşların Yetkilendirilmesi ve Faaliyetleri Hakkında Yönetmelik. Resmi Gazete. No:26333.

Bankacılık Düzenleme ve Denetleme Kurumu (2011). Bankaların Bağımsız Denetim Gerçekleştirecek Kuruluşların Yetkilendirilmesi ve Faaliyetleri Hakkında Yönetmelik. Resmi Gazete. No:28006.

Bekçi, İ. ve Gör. Y. (2015). Kurumsal Yönetim Uygulamalarının Denetim Kalitesine Etkisi Üzerine Bir Araştırma. Çankırı Karatekin Üniversitesi Sosyal Bilimler Enstitüsü Dergisi, 7(1), 165-194.

Blandon, J.G. and Bosch, J.M.A. (2013). Audit Firm Tenure and Qualified Opinions: New Evidence from Spain. Spanish Accounting Review, 16 (2).

Burton, J.C. and Roberts. W. (1967). A Study of Auditor Changes. The Journal of Accountancy, 123(4), 31-36.

Cameran, M., Prencipe, A. and Trombetta, M. (2014). Mandatory Audit Firm Rotation and Audit Quality:Evidence from the Italian Setting. European Accounting Review, 25(1), 35-58.

Carpenter, C.G. and Strawser, R.H. (1971). Displacement of Auditors When Clients Go Public. The Journal of Accountancy, 131(6), 55-58. 
Cengiz, S. ve Gör, Y. (2016). Kurumsal Yönetim Uygulamaları ve Denetim Kalitesi Arasındaki İlişki: Borsa İstanbul Kurumsal Yönetim Endeksinde Bir Araştırma. Mali Çözüm, 136, 61-84.

Chow, C.W. and. Rice, S.J (1982). Qualified Audit Opinions and Auditor Switching. The Accounting Review, 57(2), 326-335.

Croissant, Y. (2020). pglm: Panel Generalized Linear Models. R package version 0.2-2. https://CRAN.R-project.org/package=pglm

Craswell, A.T. (1988). The Association Between Qualified Opinions and auditor Switches. Accounting and Business Research, 19(73), 23-31.

Cömert, N. Uzay, Ş. Kardeş Selimoğlu, S. ve Uyar, S. (2015). Uluslararası Denetim Standartları Kapsamında Bağımsız Denetim, Sakarya Üniversitesi, Şubat.

Davidson III, W.N., Jiraporn, P. and DaDalt, P. (2006). Causes And Consequences of Audit Shopping: An Analysis of Auditor Opinions, Earnings Management, And Auditor Changes. Quarterly Journal of Business and Economics, 45(1-2), 69-87.

Deangelo, L.E. (1981). Auditor Independence, 'Low-Balling' and Disclosure Regulation. Journal of Accounting and Economics, 3(2), 113-127.

Dye, R.A. (1991). Informationally Motivated Auditor Replacement, Journal of Accounting and Economics, 14(4), 347-374.

Gegzna, V. (2020). Biostat: Routines for Basic (Bio)Statistics. https://gegznav.github.io/biostat/, https://github.com/gegznav/biostat/.

Gönen, S. ve Rasgen, M. (2016). Bağımsız Denetimde Zorunlu Denetçi Rotasyonu. İnsan ve Toplum Bilimleri Araştırmaları Dergisi, 5(7), 1809-1822.

Harris, K. (2012). Mandatory Audit Rotation: An International Investigation, Dissertation Presented to the Academic Faculty of the C.T. Bauer College of Business University of Houston.

Haskins, M.E. and Williams, D.D. (1990). A Contingent Model of Intra Big Eight Auditor Changes. Auditing: A Journal of Practice and Theory, 9(3), 55-74.

Hudaib, M. and Cooke, T.E. (2005). The Impact of Managing Director Changes and Financial Distress on Audit Qualification and Auditor Switching. Journal of Business Finance \& Accounting, 32(9-10), 1703-1739.

Karataş, M. (2014). Şirket Denetçiliğinden Bağımsız Denetçiliğe. Muhasebe ve Denetime Bakış, 43, $123-140$.

Kalkavan, H. and Ersin, I. (2019). Determination of Factors Affecting the South East Asian Crisis of 1997 Probit-Logit Panel Regression: The South East Asian Crisis. in Handbook of Research on Global Issues in Financial Communication and Investment Decision Making, IGI Global, 148-167.

Karlson, K. B., Holm, A., and Breen, R. (2012). Comparing Regression Coefficients Between SameSample Nested Models Using Logit and Probit: A New Method. Sociological Methodology, 42(1), 286-313.

Kurt, O. (2015). Bă̆ımsız Denetim Firmalarının Organizasyonu ve Bir Uygulama, İstanbul Ticaret Üniversitesi Sosyal Bilimler Enstitüsü Yayımlanmamış Yüksek Lisans Tezi, İstanbul.

Lennox, C.S. (2000). Do Companies Successfully Engage in Opinion-Shopping? Evidence from the U.K. Journal of Accounting and Economics, 29(3), 321-337. 
Lennox, C.S., Wu, X. and Zhang, T. (2014). Does Mandatory Rotation of Audit Partners Improve Audit Quality?. The Accounting Review, 89(5), 1775-1803.

Mackintosh, I. (2014). The İmportance and Challenges of Establishing Standards for Global Finance, IASB at the Manchester Business School.

Mohamed, D. M. and Habib, M. H. (2013). Auditor independence, audit quality and the mandatory auditor rotation in Egypt. Education. Business and Society: Contemporary Middle Eastern Issues, 6 (2), $116-144$.

Ocak, M. (2016). Kar Yönetimi, Bağımsız Denetim Görüşü ve Denetim Firması Değişimi Arasındaki İlişkiler: Borsa İstanbul İmalat Sektörüne Yönelik Bir Araştırma. Business and Economics Research Journal, 7(3), 89-110.

R Core Team (2021). R: A language and environment for statistical computing. R Foundation for Statistical Computing, Vienna, Austria. URL https://www.R-project.org/.

Salleh, K. and Jasmani, H. (2014). Audit Rotation and Audit Report: Empirical Evidence from Malaysian PLCS over the Period of Ten Years. Procedia - Social and Behavioral Sciences, 145, 40-50.

Sayar, A.R.Z. ve Karataş. M. (2017). Muhasebe Denetimi Alanında Yaşanan Son Gelişmeler ile Muhasebe Mesleğinde Yeni Trendler. Mali Çözüm, 139, 13-28.

Schwartz, K.B. and Menon. K. (1985). Auditor Swithes by Failing Firms. The Accounting Review, 60(2), 248-261.

Sermaye Piyasası Kurulu (2002). Seri:X No:19

Sermaye Piyasası Kurulu (2006). Seri: X, No: 22 Sermaye Piyasasında Bağımsız Denetim Standartları Hakkında Tebliğ. Resmi Gazete. No:26196.

Sermaye Piyasası Kurulu (2009). Seri: X, No: 25 Sermaye Piyasasında Bağımsız Denetim Standartları Hakkında Tebliğde Değişiklik Yapılmasına Dair Tebliğ. Resmi Gazete. No:27387.

Sermaye Piyasası Kurulu (2011). Seri: X, No: 27 Sermaye Piyasasında Bağımsız Denetim Standartları Hakkında Tebliğde Değişiklik Yapılmasına Dair Tebliğ". Resmi Gazete. No:27886

Şavlı, T. (2016). Türkiye'de Bağımsız Denetimde Rotasyon: Düzenlemeler, Uygulamalar ve Öneriler. Mali Çözüm, 134, 37-57.

Stanisic, N., Petrovic, Z., Vicentijevic K. and Mizdrakovic. V. (2014). Auditor Switching and Qualified Audit Opinion: Evidence from Serbia. Singidunum Journal of Applied Sciences. Doi:10.15308/sinteza-2014-552-558.

Teoh, S. H. (1992). Auditor Independence, Dismissal Threats and the Market Reaction to Auditor Switches. Journal of Accounting Research, 30(1), 1-23.

Tuan, K. (2015). Bağımsız Denetimde Rotasyon Uygulaması: Sistemin Artıları-Eksileri Üzerine Tartışmalar. Akademik Sosyal Araştırmalar Dergisi, 3(16), 291-309.

Türk Dil Kurumu, www.tdk.gov.tr, (Erişim Tarihi: 21.03.2021).

Warren, C.S. (1980). Uniformity of Auditing Standards: A Replication. Journal of Accounting Research, 18(1), 312-324.

Willenborg, M. (1999). Empirical Analysis of the Economic Demand for Auditing in the Initial Public Offerings Market. Journal of Accounting Research, 37(1), 225-239.

Williams, D.D. (1988). The Potential Determinants of Auditor Change. Journal of Business Finance \& Accounting, 5(2), 243-261. 
Wines, G. (1994). Auditor Independence, Audit Qualifications and the Provision of Non-Audit Services: A Note. Accounting and Finance, 34(1), 75-86.

Woo, E.S. and Koh. H.C. (2001). Factors Associated with Auditor Changes: A Singapore Study. Accounting and Business Research, 31(2), 133-144.

Yaşar, A. (2015). Olumsuz Denetim Görüşü ve Bağımsız Denetçi Değişikliği Arasındaki İlişki: Borsa İstanbul Sanayi Şirketleri Üzerine Bir Uygulama. Muhasebe ve Finansman Dergisi, 65, 81-96.

Yazar, B.B. Güneş, R. ve Çukacı, Y.C. (2018). Alınan Bağımsız Denetim Hizmetinin Kalite Kontrol Sistemi Bağlamında Değerlendirilmesi: BİST 100 Örneği. Süleyman Demirel Üniversitesi İktisadi ve İdari Bilimler Fakültesi Dergisi, 23(3), 1071-1083. 